\title{
Temporal Analysis of Temperature and Precipitation Trends in Shaheed Benazir Abad Sindh, Pakistan
}

\author{
Saleem Raza Samo \\ Energy \& Environment Dpt, \\ Quaid-e-Awam University of \\ Engineering, Science \& \\ Technology, Nawabshah, Pakistan \\ sfaizsamo@yahoo.com
}

\author{
Nadeem-ul-Karim Bhatti \\ Civil Engineering Dpt, Quaid-e- \\ Awam University of Engineering, \\ Science \& Technology, Larkana, \\ Pakistan \\ knadeem_b@quest.edu.pk
}

\author{
Abdullah Saand \\ Civil Engineering Dpt, Quaid-e- \\ Awam University of Engineering, \\ Science \& Technology, \\ Nawabshah, Pakistan \\ abdullah@quest.edu.pk
}

\author{
Manthar Ali Keerio \\ Civil Engineering Dpt, Quaid-e-Awam \\ University of Engineering, Science \& Technology \\ Nawabshah, Pakistan \\ mantharali99@quest.edu.pk
}

\author{
Daddan Khan Bangwar \\ Civil Engineering Dpt, Quaid-e-Awam \\ University of Engineering, Science and Technology, \\ Nawabshah, Pakistan \\ daddan@quest.edu.pk
}

\begin{abstract}
Temperature and precipitation variations have a huge environmental, social and economic impact. This study aims to analyze the temporal variation of temperature and precipitation in Shaheed Benazir Abad district by using the linear regression method, the trend magnitude, the Mann-Kendall test and the Sen's estimator of slope. The annual precipitation and monthly temperature data of Shaheed Benazir Abad for the period of 1996-2014 are considered. The result shows that the Diurnal temperature range of all months is decreasing due to the increasing of monthly minimum temperature at a faster rate than the monthly maximum temperature. However, the Diurnal temperature range of extreme events is increasing. The results obtained by using Mann-Kendall test revealed that rainfall exhibits significant positive trend. The trends of rainfall and rainy days show that the amount of rainfall is increasing much more rapidly than that of rainy days which indicates the occurrence of heavy events.
\end{abstract}

Keywords-Rainfall; Diurnal temperature range; Mann-Kendall test; Shaheed Benazir Abad

\section{INTRODUCTION}

Historical trends in surface climate components (like temperature and precipitation) have received significant concentration recently. To forecast climate shift loss of biodiversity, droughts, agricultural productivity, floods, precipitation and changes in temperature pattern need to be examined [1]. So the trends of precipitation and air temperature are very important to the analysis in the fields of climate sciences and hydrology [2]. But simultaneously, climate extremes are getting great attention [3]. These short duration episodes of extreme events of temperature and precipitation are responsible for huge environmental and socio-economic consequences [4-6]. Various studies have been conducted to examine the trends in precipitation and temperature records.
Authors in [3] have found negative DTR trends in the south Asia. Authors in [7] showed that between 1965 and 2009 extreme events of both maximum and minimum temperature are increasing throughout Pakistan. Authors in [8] analyzed precipitation changeability across 15 locations of Swat River basin, Pakistan, over a 51-year study period (1961-2011) and showed a mix of positive (increasing) and negative (decreasing) patterns of monthly, seasonally, and annually precipitation. In Iran, trends in extreme precipitation for the period 1951-2007 have been investigated by authors in [9] who found a strong upward trend. Various studies all over the world concluded that the frequency and intensity of extreme climate events are rising. However the causes of such anomalies are not clearly known yet but the impacts of different factors like ElNino/La-Nina [10], different atmospheric oscillations [11], anthropogenic activities and intergalactic gravitational forces [12] have been analyzed. The relative to temperature, the longterm behavior of precipitation is characterized by larger spatial variability, demonstrating a proportionately higher dependence on local and regional variables. In this case, relatively smallscale analysis might be essential in practical applications [2]. The aim of this study is to examine the historical variability in temperature and precipitation trends of (1996-2014) over Shaheed Benazir Abad district, Sind, Pakistan.

\section{DATA AND METHODOLOGY}

\section{A. Study Area Description}

Shaheed Benazir Abad is located at the center of Sindh province of Pakistan whose geographical coordinates are $26^{\circ}$ $15^{\prime} 0^{\prime \prime}$ North, $68^{\circ} 25^{\prime} 0^{\prime \prime}$ East. Indus river is flowing at west border. The climate is tropical. The total projected population of the city was 1676000 in 2014 . The area of the city is 4502 $\mathrm{km}^{2}$. The average rainfall in the district is $18.39 \mathrm{~cm}$. The data 
of Pakistan Meteorological Department (PMD) station at the airport of Nawabshah (OPNH-417490) was used for this study [13].

\section{B. Methods}

Monthly and annually minimum and maximum surface air temperatures, Diurnal Temperature Range (DTR) and rainfall have been compiled for the years 1996 - 2014. The linear regression method is used to analyze the behavior of temperature and precipitation. The graphs of the temperature and rainfall for the 12 months of each year (228 months for the 19 year study period) were plotted. Monthly graphs were then combined in a spreadsheet with the minimum, maximum DTR and rainfall of each month and then the trend line for every variable was plotted. Various statistical procedures and techniques are used to detect and estimate trends in different climate parameters. These various statistical methods are broadly divided into parametric and non-parametric ones. Parametric methods specially assume the normal distribution of concerned data while non-parametric methods are those which consider that the concerned data do not follow a specific distribution [2]. Four statistical methods were used to detect and estimate the trends of temperature, humidity and precipitation. Firstly, linear regression method was used to calculate the trend for each time series [14]. The trend magnitude was found by using the position of trend equation. The Mann-Kendall test was used to investigate the significance of all trends [15]. The Sen's slope was used to determine the magnitude of all trends [16].

1) The Linear Regression Method

The behavior of all parameters was computed and analyzed with following linear trend model by using linear regression method [17].

$$
y=\alpha x+\beta
$$

where $\alpha$ represents the slope of equation and $\beta$ represents the $y$ intercept and are calculated as:

$$
\begin{gathered}
\alpha=\frac{\sum y_{j} \sum x_{j}{ }^{2}-\sum x_{j} \sum x_{j} y_{j}}{n \sum x_{j}^{2}-\left(\sum x_{j}\right)^{2}} \\
\beta=\frac{n \sum y_{j} x_{j}-\sum x_{j} \sum y_{j}}{n \sum x_{j}^{2}-\left(\sum x_{j}\right)^{2}}
\end{gathered}
$$

where $\mathrm{x}_{\mathrm{j}}$ represents "years" and $\mathrm{y}_{\mathrm{j}}$ represents "Parameters". This method is frequently used to determine the trend. If the sign of $\alpha$ is positive then the trend is increasing and if the sign of $\alpha$ is negative then the trend is decreasing. When the value of $\alpha$ is equal to zero then there is no trend in time series.

2) The Trend Magnitude

The second method was used to find out the trend magnitude. It was calculated by using:

$$
\Delta y=y(\text { initial point })-y(\text { terminate point })
$$

where $\Delta y$ shows the total trend magnitude while y (initial point) and $y$ (terminate point) represent the beginning and the end point of the trend equation respectively. The positive and negative sign of $\Delta y$ show the decreasing and increasing trend respectively.

\section{3) The Mann-Kendal Test}

The significance of trends of all time series of present study was assessed by using the Mann-Kendall test. It is a nonparametric test which is widely used in hydrological and climatological time series [18]. The World Meteorological Organization (WMO) has suggested the Mann-Kendall test for assessing the temporal trends in the time series of environmental data [19].This method was used to detect the statistically significant trends of long term data. There are two hypotheses to be tested in the Mann-Kendall test .One hypothesis is the null hypothesis $\mathrm{H}_{0}$ which means that there is no trend in concerned time series while the other one is the alternative hypothesis $\mathrm{H}_{a}$. This alternative hypothesis assumes that there is significant trend in the time series. The MannKendall Statistic (S) is computed as follows:

$$
S=\sum_{i=1}^{n-1} \sum_{j=i+1}^{n} \operatorname{sign}(T j-T i)
$$

where,

$$
\operatorname{sign}(T j-T i)=\left\{\begin{array}{l}
1 \text { if } \mathrm{T}_{j}>T_{i} \\
0 \text { if } \mathrm{T}_{j}=T \\
-1 \text { if } \mathrm{T}_{j}<T
\end{array}\right\}
$$

Here $\mathrm{Tj}$ and $\mathrm{Ti}$ represent the data points at the time $\mathrm{i}$ and $\mathrm{j}$ respectively where $\mathrm{j}>\mathrm{i}$ and $\mathrm{n}$ is the last period in the time series. If $n>10$ then the Statistic $S$ approximately normally distributed with the mean of $\mathrm{S}$ is zero, the variance statistic $\operatorname{VAR}(\mathrm{S})$ is computed as

$$
\operatorname{VAR}(S)=\frac{1}{18} n(n-1)(2 n+5)
$$

Kendall's tau $(\tau)$ is obtained by applying Mann-Kendall test. It represents the correlation between two variables which means the value of tau describe the relationship between two variables [20]. Mann-Kendall $\tau$ is given by

$$
\tau=\frac{S}{n(n-1) / 2}
$$

Here, S represents the Mann-Kendall statistic and $n$ shows the number of data pairs. The probability $\mathrm{p}$ is determined to know the confidence level in the hypothesis of Mann-Kendall test and it is computed as follows

$$
p=[1-f(Z)] \cdot 100
$$

$\mathrm{Z}$ is standard normal test statistics which is computed by using the following equation:

$$
Z=\left\{\begin{array}{l}
\frac{S-1}{\sqrt{\operatorname{VAR}(S)}} \text { if } S>0 \\
0 \text { if } S=0 \\
\frac{S+1}{\sqrt{\operatorname{VAR}(S)}} \text { if } S>0
\end{array}\right\}
$$


In the equation $(9), f(Z)$ is a function of probability density and it is calculated by following equation:

$$
f(Z)=\frac{1}{\sqrt{2 \pi}} e^{-\frac{z^{2}}{2}}
$$

The value of $p$ is very important for accepting and rejecting the hypothesis of Mann-Kendall test. The level of chosen significance is represented by Alpha $(\alpha=0.05)$. If the calculated value of $p$ is greater than the value of $\alpha$ then $\mathrm{H}_{\mathrm{o}}$ cannot be rejected. If the value of $p$ is less than the value of Alpha then $\mathrm{H}_{\mathrm{a}}$ should be accepted [15].

4) The Sen's Estimator of Slope

This is a non-parametric method used to calculate the magnitude of linear trends which exist in time series data. The slope $\left(\mathrm{m}_{\mathrm{i}}\right)$ of all pairs of data is computed by (12).

$$
m_{i}=\frac{x_{j}-x_{k}}{j-k}
$$

In the above equation, $x_{j}$ and $x_{k}$ represent data values at the time $\mathrm{j}$ and $\mathrm{k}$ respectively where $\mathrm{j}>\mathrm{k}$. The Sen's estimator of slope is the median of these $\mathrm{N}$ values of $\mathrm{m}_{\mathrm{i}}$. The sign of $\mathrm{m}_{\text {med }}$ indicates the reflection of trend of time series data. The positive sign of $m_{\text {med }}$ represents the increasing trend while negative sign shows the decreasing trend [21]. Addinsoft's XLSTAT 2015 was used for Mann-Kendall test and Sen's estimator of slope. The hypothesis was tested at $95 \%$ confidence level for all variables.

\section{RESULTS AND ANALYSIS}

From the computed data, it was observed that the most critical section is, when tunnel face aligns the pile group center line (monitoring section). However, there are not any significant changes in surface settlement as tunnel face passes beyond the $y / D \geq 3$ from the monitoring section. Therefore, it can be assumed that monitoring section attain the plane strain condition.

\section{A. Trends in Air Temperature}

Maximum, minimum air temperature and monthly diurnal air temperature range of Shaheed Benazir Abad have been illustrated in Figure 1 for the period of 1996-2014. Figure 1(a) shows the fluctuations of DTR during study period due to various factors but the linear trend of DTR is decreasing steadily by a aslope of $-0.05789^{\circ} \mathrm{C}$ per year during this 19 year period. Specially, the decreasing trend of diurnal temperature range (DTR) is more significant during recent years. Figure 1(b) shows the behavior of monthly maximum temperature which is slightly increasing with the rate of $0.000519^{\circ} \mathrm{C} /$ year, but the monthly minimum temperature is rising at a more faster rate, $0.06315^{\circ} \mathrm{C} /$ year as shown in Figure 1(c). Therefore, the significantly increasing trend of minimum temperature contributes to the decrease of diurnal temperature range. The investigation revealed that annual maximum temperature event during 1996-2014 has a rising trend and the rate of increase is $0.0736^{\circ} \mathrm{C}$ per year. This increase detected in maximum temperature events over the observed period, indicates that overall, days are getting warmer in Shaheed Benazir Abad. On the contrary the annual minimum temperature event during the study period shows a decreasing trend at a rate of $0.014^{\circ} \mathrm{C}$ per year. This decrease detected in minimum temperature events over the observed period indicates that overall, nights are becoming cooler in Shaheed Benazir Abad. These changes in temperature extremes ultimately contributed to the increase of the linear trend of DTR event which increases at the rate of $0.0357^{\circ} \mathrm{C}$ per year during $1996-2014$ (Figure 2).

\section{B. Trends in Rainfall}

The investigation of the variations in the precipitation patterns over the Shaheed Benazir Abad indicates that there is a sharp increase in the linear trend of amount of rainfall during 1996-2014. The total amount of rainfall is increasing and the period of rainfall is also increasing. The average number of rainy days is 9.84 . The trends of rainfall and its period indicate that the amount of rainfall is increasing much more rapidly than the number of rainy days, indicating the more frequent occurrence of heavy events (Figure 3 ). The average annual precipitation in Shaheed Benazir Abad is $18.39 \mathrm{~cm}$. However, several years may pass without significant rainfall while unprecedented rainfalls occurred in 2011 [22].

\section{Trend Analysis by Mann-Kendall Test}

The trends of temperature and rainfall in Shaheed Benazir Abad were detected by using Mann-Kendall test. Tables I and II summarize the results obtained by applying Mann-Kendall test on time series of temperature and rainfall. The significance level was the same $(\alpha=5 \%)$ for all parameters. The results revealed that four parameters have positive trends and remaining three parameters have negative trends as indicated in Table II. The P -values of six parameters are greater than Alpha value (significance level) as indicated in Table I which means that one can not reject the hypothesis $\mathrm{H}_{\mathrm{o}}$. These values show that six parameters have insignificant trends. While the P-value of time series of rainfall is less than the value of Alpha which is interpreted that the hypothesis $\mathrm{H}_{\mathrm{o}}$ should be rejected. It means that significant trend was detected for all month's rainfall in Shaheed Benazir Abad during study period. Sen's estimator of slope was used to find out the magnitude of slopes of trends of temperature and rainfall in the study area. The result shows that precipitation exhibits significant increasing trend with slope of 22.07 and having $24.2105 \mathrm{~mm} /$ year magnitude.

\section{DISCUSSION AND CONCLUSION}

There are five positive trends in time series and two negative trends according to the investigation of trend equation. But, the application of Mann-Kendall test revealed that there was only one positive trend which was statistically significant while there were no significant trends in the remaining time series. According to the trend equation investigation, the maximum and minimum temperature increased in the past 19 years by $0.000519^{\circ} \mathrm{C}$ per year and $0.06315^{\circ} \mathrm{C}$ per year respectively, while the diurnal temperature range (DTR) reduced by $0.05^{\circ} \mathrm{C}$ per year which is mostly because of the higher rate of increase for $\mathrm{T}_{\min }$ relative to $\mathrm{T}_{\max }$. Trends of 
extreme temperature indicate that maximum temperature event is rising at the rate of $0.0736^{\circ} \mathrm{C}$ per year and minimum temperature event is decreasing at the rate of $0.014^{\circ} \mathrm{C}$ per year. The linear trend of DTR event is increasing at the rate of $0.0357^{\circ} \mathrm{C}$ per year. The investigation of the variations in the precipitation trends suggests that the total amount of rainfall is increasing and also the period of rainfall is increasing. However, the slope of linear trend of rainfall and its period show that the amount of rainfall is increasing much more rapidly than the number of rainy days which indicates the occurrence of heavy events. Many years have passed without significant rainfall and unprecedented rainfall of about $650 \mathrm{~mm}$ occurred in 2011 which created havoc in the city. This extreme event of rainfall disturbed the whole ecosystem of the region. It can be concluded that extreme events are a driving force for climate change in SBA.

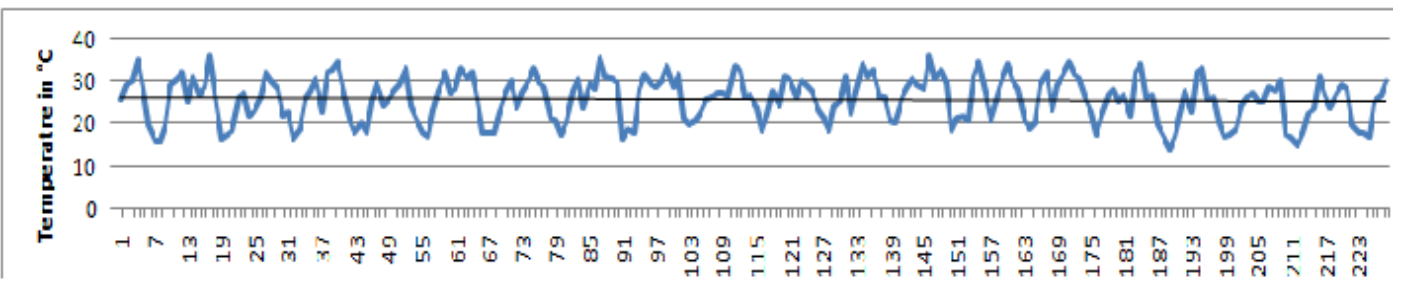

(a) Monthly diurnal temperature range

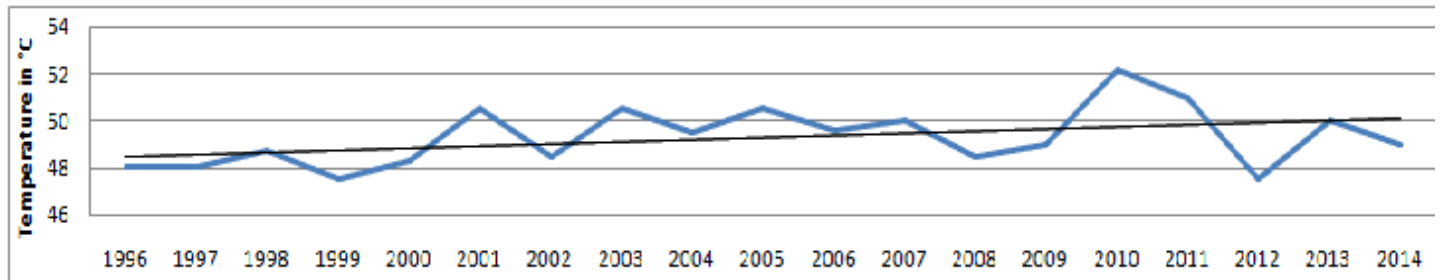

(b) Monthly maximum temperature

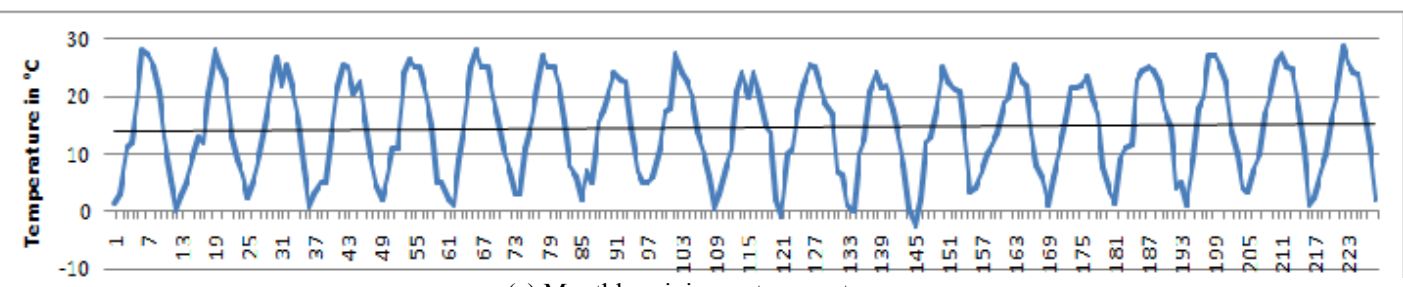

(c) Monthly minimum temperature

Fig. 1. All months temperature variation in Shaheed Benazir Abad

TABLE I. STATISTICS BY MANN-KENDALL TEST OF TEMPERATURE AND RAINFALL

\begin{tabular}{|c|c|c|c|c|c|}
\hline Parameters & $\begin{array}{l}\text { Mann-Kendall } \\
\text { Statistic(S) }\end{array}$ & Kendall's Tau & P-value & Alpha & Test Interpretation \\
\hline Tmax & -96.00 & -0.004 & 0.533 & 0.05 & Accept $\mathrm{H}_{\mathrm{o}}$ \\
\hline Tmin & 571 & 0.022 & 0.309 & 0.05 & Accept $\mathrm{H}_{\mathrm{o}}$ \\
\hline DTR & -1186 & -0.047 & 0.850 & 0.05 & Accept $\mathrm{H}_{0}$ \\
\hline Tmax(Event) & 36 & 0.241 & 0.091 & 0.05 & Accept $\mathrm{H}_{0}$ \\
\hline Tmin(Event) & -19 & -0.128 & 0.754 & 0.05 & Accept $\mathrm{H}_{\mathrm{o}}$ \\
\hline DTR(Event) & 36 & 0.238 & 0.092 & 0.05 & Accept $\mathrm{H}_{\mathrm{o}}$ \\
\hline Rainfall & 107 & 0.626 & 0.0001 & 0.05 & Reject $\mathrm{H}_{\mathrm{o}}$ \\
\hline
\end{tabular}

TABLE II. NATURE OF TRENDS AND THEIR MAGNITUTES

\begin{tabular}{|c|c|c|c|c|}
\hline Parameters & $\begin{array}{c}\text { Mann-Kendall } \\
\text { Test Nature }\end{array}$ & Trend Significance & Sen's slope & Magnitude of Trend \\
\hline Tmax & Negative & No & 0.00 & $0.00052\left({ }^{\circ} \mathrm{C} /\right.$ year $)$ \\
\hline Tmin & Positive & No & 0.003 & $0.06315\left({ }^{\circ} \mathrm{C} /\right.$ year $)$ \\
\hline DTR & Negative & No & -0.006 & $0.05789\left({ }^{\circ} \mathrm{C} /\right.$ year $)$ \\
\hline Tmax(Event) & Positive & No & 0.083 & $0.07368\left({ }^{\circ} \mathrm{C} /\right.$ year $)$ \\
\hline Tmin(Event) & Negative & No & -0.067 & $0.01421\left({ }^{\circ} \mathrm{C} /\right.$ year $)$ \\
\hline DTR(Event) & Positive & No & 0.154 & $0.03578\left({ }^{\circ} \mathrm{C} /\right.$ year $)$ \\
\hline Rainfall & Positive & Yes & 22.07 & $24.2105(\mathrm{~mm} /$ year $)$ \\
\hline
\end{tabular}




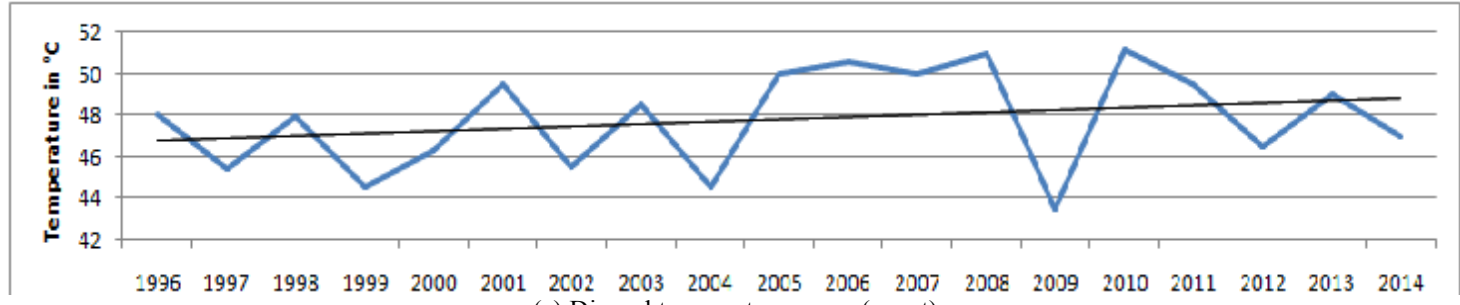

(a) Diurnal temperature range (event)

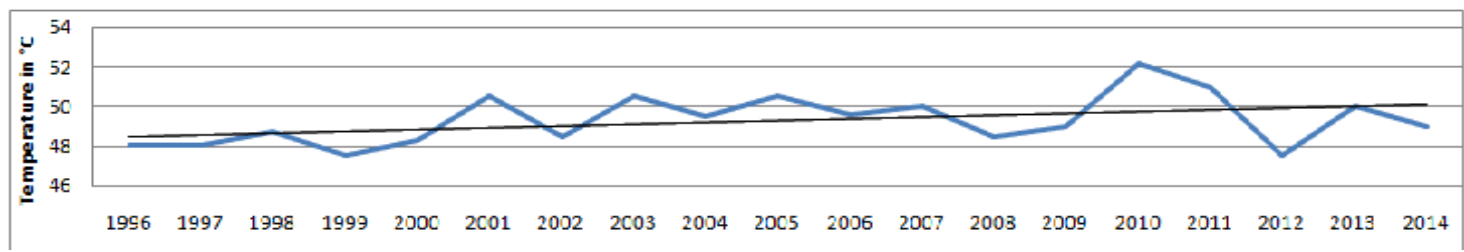

(b) Maximum temperature (event)

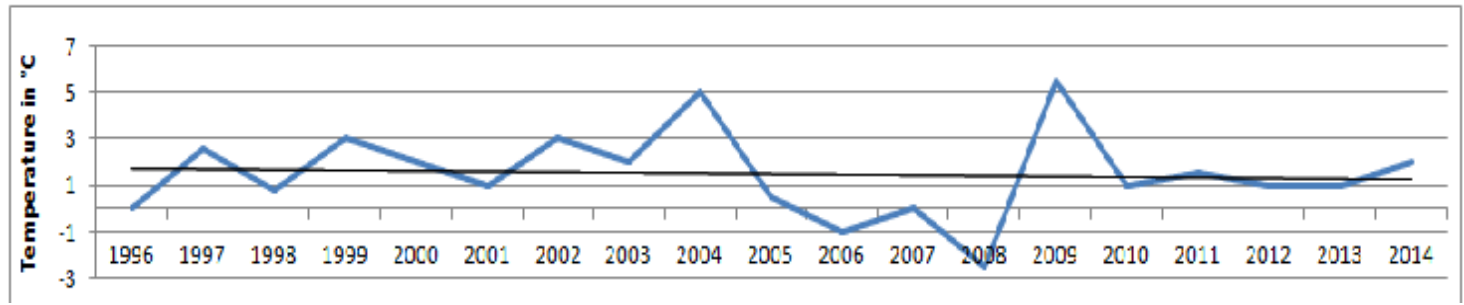

(c) Minimum temperature (event)

Fig. 2. Annual extreme events of temperature variation in the Shaheed Benazir Abad

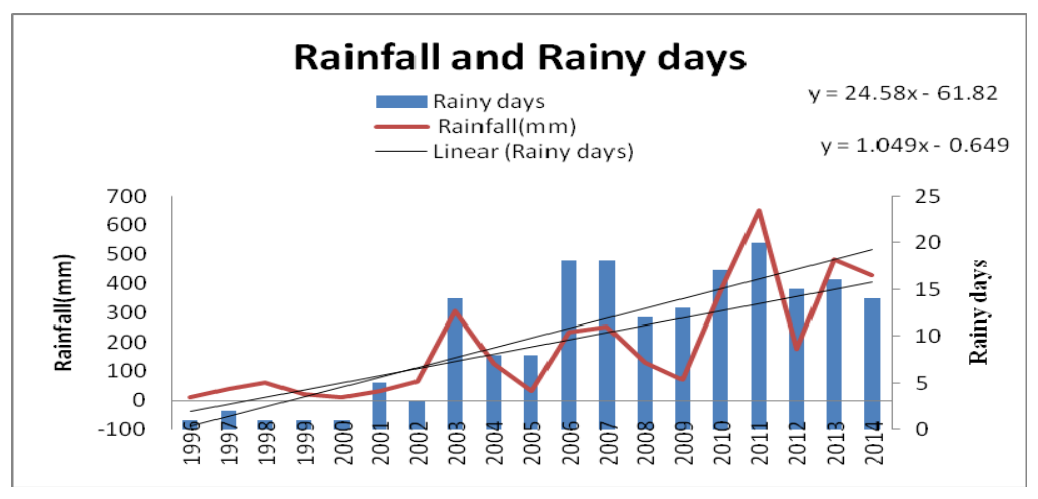

Fig. 3. Total annual rainfall and number of rainy days in the year of the SBA.

\section{REFERENCES}

[1] G. A. Uzochukwu, K. Schimmel, V. Kabadi, S. Y. Chang, T. Pinder, S. A. Ibrahim, Proceedings of the 2013 National Conference on Advances in Environmental Science and Technology,Springer, 2015

[2] S. Chattopadhyay, D. R Edwards "Long-term trend analysis of precipitation and air temperature for Kentucky, United States", Climate, Vol. 4, No. 10, 2016

[3] A. M. G. Klein Tank, T. C. Peterson, D. A. Quadir, S. Dorji, X. Zou, H. Tang, K. Santhosh, U. R. Joshi, A. K. Jaswal, R. K. Kolli, A. B. Sikder, N. R. Deshpande, J. V. Revadekar, K. Yeleuova, S. Vandasheva, M. Faleyeva, P. Gomboluudev, K. P. Budhathoki, A. Hussain, M. Afzaal, L. Chandrapala, H. Anvar, D. Amanmurad, V. S. Asanova, P. D. Jones, M. G. New, T. Spektorman, "Changes in daily temperature and precipitation extremes in central and south Asia", Journal of Geophysical Research: Atmospheres, Vol. 111, No. D16, 2006
[4] D. R. Easterling, J. L. Evans, P. Y. Groisman, T. R Karl, K. E. Kunkel, P. Ambenje, "Observed variability and trends in extreme climate events: a brief review", Bulletin of the American Meteorological Society, Vol. 81, No. 3, pp. 417-425, 2000

[5] R. Grotjahn, R. Black, R. Leung, M. F. Wehner, M. Barlow, M. Bosilovich, A. Gershunov, W. J. Gutowski Jr, J. R. Gyakum, R. W. Katz, Y. Y. Lee. "North American extreme temperature events and related large scale meteorological patterns: a review of statistical methods, dynamics, modeling, and trends", Climate Dynamics, Vol. 46, No. 3-4, pp. 1151-1184, 2016

[6] Y. Guan, X. Zhang, F. Zheng, B. Wang, "Trends and variability of daily temperature extremes during 1960-2012 in the Yangtze River Basin, China", Global and Planetary Change, Vol. 124, pp. 79-94, 2015

[7] M. Zahid, G. Rasul, "Frequency of extreme temperature and precipitation events in Pakistan 1965-2009", Science International, Vol. 23, No. 4, pp. 313-9, 2011 
[8] I. Ahmad, D. Tang, T. F. Wang, M. Wang, B. Wagan, "Precipitation trends over time using Mann-Kendall and spearman's rho tests in swat river basin, Pakistan", Advances in Meteorology, Vol. 2015, Article ID 431860, 2015

[9] R. C. Balling Jr., M. S. Keikhosravi Kiany, S. Sen Roy, J. Khoshhal, "Trends in extreme precipitation indices in Iran: 1951-2007", Advances in Meteorology, Vol. 2016, Article ID 2456809, 2016

[10] S. S. Roy, G. B. Goodrich, R. C. Balling Jr, "Influence of El Nino/southern oscillation, Pacific decadal oscillation, and local seasurface temperature anomalies on peak season monsoon precipitation in India”, Climate Research, Vol. 25, pp. 171-178, 2003

[11] I. Tosic, M. Zorn, J. Ortar, M. Unkasevic, M. B. Gavrilov, S. B. Markovic, "Annual and seasonal variability of precipitation and temperatures in Slovenia from 1961 to 2011", Atmospheric Research. Vol. 168, pp. 220-33, 2016

[12] M. A. A. Beg, "Astronomic - tectonic interaction in governance of climate change", 3rd International Energy \& Environment Conference, 2015

[13] TuTiempo, Average annual climate values for Nawabshah during 1996-2014. Available from: http://www.tutiempo.net/en/Climate

[14] N. Sadiq, M. S. Qureshi, "Climatic variability and linear trend models for the five major cities of Pakistan", Journal of Geography and Geology, Vol. 2, No. 1, 83-92, 2010

[15] M. B. Gavrilov, S. B. Markovic, A. Jarad, V. M. Korac, "The analysis of temperature trends in Vojvodina (Serbia) from 1949 to 2006", Thermal Science, Vol. 19, pp. 339-350, 2015
[16] M. Gocic, S. Trajkovic, "Analysis of changes in meteorological variables using Mann-Kendall and Sen's slope estimator statistical tests in Serbia", Global and Planetary Change, Vol. 100, pp. 172-82, 2013

[17] I. Ahmad, S. Zhaobo, D. Weitao, R. Ambreen, "Trend analysis of January temperature in Pakistan over the period of 1961-2006, Geographical Perspective", Pakistan Journal of Meteorology. Vol. 7, No. 13, pp. 11-22, 2010

[18] C. J. Martinez, J. J. Maleski, M. F. Miller, "Trends in precipitation and temperature in Florida, USA", Journal of Hydrology, Vol. 452453, pp. 259-281, 2012

[19] P. Shi, X. Ma, X. Chen, S. Qu, Z. Zhang, "Analysis of variation trends in precipitation in an upstream catchment of Huai River", Mathematical Problems in Engineering, Vol. 2013, Article ID 929383, 2013

[20] G. Yadav, D. N. Mishra, K. Prashanthi, S. Chaturvedi, "Air Pollution Trend Analysis Using Sen Estimator Method - A Survey", International Journal of Science and Research, Vol. 4, No. 3, 2015

[21] H. Tabari, P. H. Talaee, "Analysis of trends in temperature data in arid and semi-arid regions of Iran", Global and Planetary Change, Vol. 79, No. 1-2, pp. 1-10, 2011

[22] A. Mahmood, N. Faisal, A. Jameel, Special Report on Pakistan's Monsoon 2011 Rainfall, Climate Data Processing Centre, Pakistan Meteorological Department, 2011 